\title{
The role of bridging ligands in dinitrogen reduction and functionalization by uranium multimetallic complexes
}

\author{
Marta Falcone', Luciano Barluzzi', Julie Andrez', Farzaneh Fadaei Tirani', Ivica Zivkovic², Alberto Fabrizio', \\ Clemence Corminboeuf', Kay Severin' and Marinella Mazzanti ${ }^{1}{ }^{1 \star}$
}

\begin{abstract}
Cooperativity between metal centres is identified as a crucial step in dinitrogen reduction both for the industrial Haber-Bosch process and for natural nitrogen fixation by nitrogenase enzymes, but the mechanism of $\mathbf{N}_{2}$ reduction remains poorly understood. This is in large part because multimetallic complexes that reduce and functionalize dinitrogen in the absence of strong alkali reducing agents are crucial to establish a structure-activity relationship, but remain extremely rare. Recently, we reported a multimetallic nitride-bridged diuranium(III) complex capable of reducing and functionalizing dinitrogen. Here we show that an analogous complex assembled with an oxo instead of a nitride linker also effects the four-electron reduction of dinitrogen, but the reactivity of the resulting oxo- $\left(\mathbf{N}_{2}\right)$ complex differs remarkably from that of the nitride- $\left(\mathbf{N}_{2}\right)$. Computational studies show a different bonding scheme for the dinitrogen where the bridging nitride does participate in the binding and consequent activation of $\mathbf{N}_{2}$, while the oxide does not.
\end{abstract}

T he transformation of the widely available and cheap dinitrogen $\left(\mathrm{N}_{2}\right)$ molecule into ammonia or into valuable fine chemicals through $\mathrm{N}-\mathrm{C}$ bond formation is an important challenge in chemistry that continues to attract a broad range of studies. The only industrial process so far that uses dinitrogen as a feedstock is the Haber-Bosch process. This is currently used for the production (from dinitrogen and dihydrogen) of the large amounts of ammonia $\left(\mathrm{NH}_{3}\right)$ required in the production of fertilizers, but requires a metal catalyst and harsh conditions (about $450{ }^{\circ} \mathrm{C}$ and 300 bar) and consumes about $2 \%$ of the world's annual energy supply. The conversion of $\mathrm{N}_{2}$ into high-value $\mathrm{N}$-containing organic products under ambient conditions would provide a new class of sustainable energy-saving nitrogen fixation processes. In this context, a wide range of studies have been directed to the development of metal complexes able to effect such reactions in mild conditions ${ }^{1-5}$. Particularly desirable would be the use of cheap and/or largely available molecules such as $\mathrm{CO}$ or $\mathrm{CO}_{2}$ in combination with dinitrogen for the synthesis of new organic products. Versatile chemical cycles for the production of isocyanates by the molecular fixation of $\mathrm{N}_{2}, \mathrm{CO}_{2}$ and $\mathrm{R}_{3} \mathrm{ECl}(\mathrm{E}=\mathrm{C}$, Si and $\mathrm{Ge})$ have been reported ${ }^{6}$. However, direct dinitrogen cleavage and $\mathrm{N}-\mathrm{C}$ bond formation from the addition to dinitrogen complexes of cheap carbonated molecules such as $\mathrm{CO}$ and $\mathrm{CO}_{2}$ remains extremely rare $\mathrm{ra}^{7,8}$.

Because iron oxide was used as a heterogeneous catalyst in the Haber-Bosch industrial process and because of the important role of iron and molybdenum in the biological reduction of dinitrogen to ammonia, most studies on molecular compounds have focused on complexes of iron and molybdenum ${ }^{9-11}$. In contrast, less attention has been devoted to molecular models based on other metals known to be active heterogeneous catalysts in the reduction of dinitrogen to ammonia, such as uranium and uranium nitride materials, as reported in an earlier patent ${ }^{12}$. Thus, molecular complexes of uranium are very attractive models to improve our understanding of dinitrogen cleavage and functionalization, which is essential for the future development of more effective catalysts.
Very recently, we reported dinitrogen reduction by a welldefined multimetallic complex of uranium ${ }^{8}$. The diuranium(III) nitride complex $\left[\mathrm{K}_{3}\left\{\left[\mathrm{U}\left(\mathrm{OSi}\left(\mathrm{O}^{t} \mathrm{Bu}\right)_{3}\right)_{3}\right]_{2}(\mu-\mathrm{N})\right\}\right]$, or $\mathrm{K}_{3} \mathrm{UNU}$, effects the four-electron reduction of dinitrogen in ambient conditions, leading to the nitride-hydrazide-bridged diuranium(v) complex $\left[\mathrm{K}_{3}\left\{\left[\mathrm{U}\left(\mathrm{OSi}\left(\mathrm{O}^{t} \mathrm{Bu}\right)_{3}\right)_{3}\right]_{2}(\mu-\mathrm{N})\left(\mu-\mathrm{N}_{2}\right)\right\}\right]$, or $\mathrm{K}_{3} \mathrm{UN}\left(\mathrm{N}_{2}\right) \mathrm{U}$ (Fig. 1). We found that the bound dinitrogen $\left(\mathrm{N}_{2}{ }^{4-}\right)$ can be cleaved by the addition of $\mathrm{CO}$ to afford cyanate. The subsequent addition of hydrogen and protons to $\mathrm{K}_{3} \mathrm{UN}\left(\mathrm{N}_{2}\right) \mathrm{U}$ affords $\mathrm{NH}_{3}$ quantitatively. Although a few examples of uranium complexes binding $\mathrm{N}_{2}$ have been reported previously ${ }^{13-17}, \mathrm{~K}_{3} \mathrm{UN}\left(\mathrm{N}_{2}\right) \mathrm{U}$ provided dinitrogen functionalization at a uranium centre. The observed reactivity is ascribed to the multimetallic binding of the bridging dinitrogen to two uranium centres and two potassium cations, which is enabled by the bridging nitride and the flexible potassium-siloxide framework. However, it remains unclear how crucial is the nature of the group (nitride) bridging the two uranium(III) atoms. We therefore set out to explore the possibility of using an oxo group as linker to build multimetallic uranium complexes.

Oxo-bridged molecular complexes are attractive models for metal oxide catalysts but usually contain metal centres in a high oxidation state. Notably, only one example of a crystallographically characterized U(III)-O-U(III) complex has been reported ${ }^{18}$. This complex and most of the reported structurally characterized diuranium(IV) oxo-bridged complexes have been obtained from the reaction of $\mathrm{U}$ (III) complexes with the solvent ${ }^{19}$ or the supporting ligand ${ }^{20}$ or with adventitious traces of $\mathrm{O}_{2}$ or water in the solvent. In contrast, the number of rationally synthesized diuranium(IV) oxobridged complexes remains limited, probably due to the tendency of these species to undergo further oxidation ${ }^{21,22-30}$.

Here, we report a novel route for the preparation of a siloxide-supported oxo-bridged diuranium(IV) complex that is easily reduced to afford a rare multimetallic oxo-bridged diuranium(III) complex. Reactivity studies allowed us to probe the effect of the 

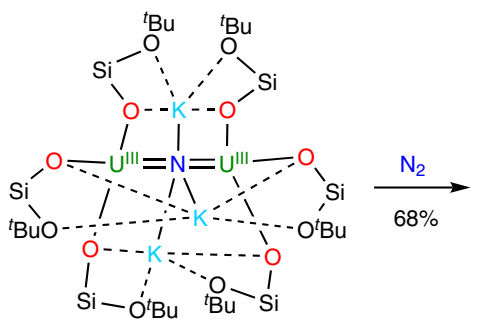

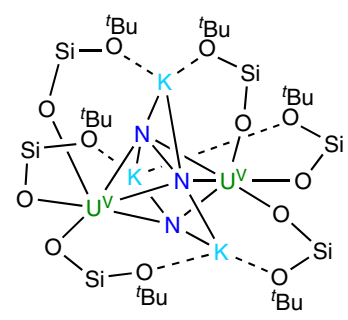

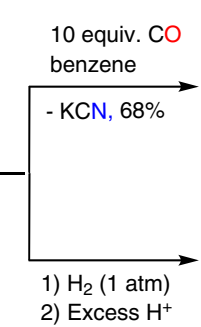
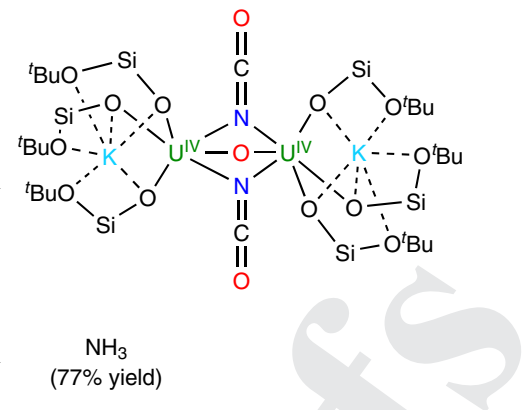

Fig. 1 Dinitrogen reduction and functionalization by a multimetallic uranium nitride. Left, Four-electron reduction of dinitrogen performed by the complex $\left[K_{3}\left\{\left[\mathrm{U}\left(\mathrm{OSi}\left(\mathrm{O}^{t} \mathrm{Bu}\right)_{3}\right)_{3}\right]_{2}(\mu-\mathrm{N})\right]\left(\mathrm{K}_{3} \mathrm{UNU}\right)\right.$ to afford complex $\left[\mathrm{K}_{3}\left\{\left[\mathrm{U}\left(\mathrm{OSi}\left(\mathrm{O}^{t} \mathrm{Bu}\right)_{3}\right)_{3}\right]_{2}(\mu-N)\left(\mu-\mathrm{N}_{2}\right)\right\}\right]\left(\mathrm{K}_{3} \mathrm{UN}\left(\mathrm{N}_{2}\right) \mathrm{U}\right)$. Right top, $\mathrm{N}_{2}$ functionalization by $\mathrm{CO}$ to afford cyanate and cyanide. Right bottom, $\mathrm{N}_{2}$ functionalization by $\mathrm{H}_{2} / \mathrm{H}^{+}$to afford ammonia. In all complexes, only the - $\mathrm{O}^{t} \mathrm{Bu}$ groups of the $\mathrm{OSi}\left(\mathrm{O}^{\mathrm{H}} \mathrm{Bu}\right)_{3}$ that are metal bound are shown.

complex core structure on the reduction and functionalization of dinitrogen, showing that the linker has a crucial role in determining the reactivity of analogous multimetallic $\mathrm{N}_{2}$ complexes.

\section{Results and discussion}

Synthesis, characterization and reactivity. Initial attempts to prepare a diuranium(IV) oxo-bridged complex from the reaction of the previously reported complex $\left[\mathrm{U}\left(\mathrm{OSi}\left(\mathrm{O}^{t} \mathrm{Bu}\right)_{3}\right)_{3}\right]_{2}(\mathbf{1})^{31}$ with common oxygen atom transfer reagents led to intractable reaction mixtures $\left(\mathrm{Me}_{3} \mathrm{NO}, \mathrm{N}_{2} \mathrm{O}\right)$ or to the isolation of complex $\left[\left\{\mathrm{U}\left(\mathrm{OSi}\left(\mathrm{O}^{\mathrm{t}} \mathrm{Bu}\right)_{3}\right)_{3}\right\}_{2}(\mu\right.$ -O)] (2) in very low yield (PyNO). However, we were able to reproducibly prepare complex 2 in $79 \%$ yield by treating 1 with the $\mathrm{N}_{2} \mathrm{O}$ adduct of the $\mathrm{N}$-heterocyclic carbene 1,3-dimesitylimidazol-2-ylidene (IMes) IMes $\mathrm{N}_{2} \mathrm{O}^{32,33}$ in THF at $-80^{\circ} \mathrm{C}$ (Fig. 2). The ability of the IMes $\mathrm{N}_{2} \mathrm{O}$ to selectively produce the oxo diuranium(IV) complex could be due to the higher reaction rates of this reagent ${ }^{34}$ compared $^{-}$ to the other used oxygen transfer agents.

The reduction of complex 2 with 5 equiv. of $\mathrm{KC}_{8}$ in $\mathrm{THF}$ at $80^{\circ} \mathrm{C}$ affords the formation of the multimetallic oxo-bridged diuranium(III) complex $\left[\mathrm{K}_{2}\left\{\left[\mathrm{U}\left(\mathrm{OSi}\left(\mathrm{O}^{t} \mathrm{Bu}\right)_{3}\right)_{3}\right]_{2}(\mu-\mathrm{O})\right\}\right]\left(\mathrm{K}_{2} \mathrm{UOU}, 3\right.$; Fig. 2), which can be isolated from a cold $\left(-80^{\circ} \mathrm{C}\right)$ THF solution with a yield of $40 \%$. The conversion rate is significantly higher ( $>$ $70 \%$ ), but isolation results in lower yields due to the low thermal stability of 3.

To investigate how the linker affects the reactivity of multimetallic complexes of uranium(iii) towards dinitrogen we investigated the reaction of $\mathbf{3}$ with $\mathrm{N}_{2}$. When a toluene solution of $\mathbf{3}$ is exposed to $\mathrm{N}_{2}$ (1 atm) at room temperature (Fig. 2), we observe an immediate change in colour from deep red to brown along with disappearance of the ${ }^{1} \mathrm{H}$ NMR signal assigned to 3 and appearance of a new peak. Dark brown crystals of the complex $\left[\mathrm{K}_{2}\left\{\left[\mathrm{U}\left(\mathrm{OSi}\left(\mathrm{O}^{t} \mathrm{Bu}\right)_{3}\right)_{3}\right]_{2}(\mu-\mathrm{O})\right.\right.$ $\left.\left.\left(\mu-\eta^{2}: \eta^{2}-\mathrm{N}_{2}\right)\right\}\right](4)$ were isolated in $70 \%$ yield from a toluene solution of 4 at $-40^{\circ} \mathrm{C}$. Proton NMR studies showed that complex 4 is stable in toluene at room temperature for several hours. No loss of $\mathrm{N}_{2}$ from 4 is observed under dynamic vacuum in the solid state or after three cycles of freeze-pump-thaw degassing under argon of a toluene solution of 4 . The cation plays a crucial role in $\mathrm{N}_{2}$ activation by the $\mathrm{K}_{2} \mathrm{UOU}$ complex. Notably, preliminary results indicate that when the potassium is replaced by Cs, $\mathrm{N}_{2}$ binding or reduction is not observed.

Variable-temperature magnetic data measured with a superconducting quantum interference device (SQUID) (Supplementary Figs. 53 and 54) for complex 4 showed the presence of two uranium ions in the formal oxidation $+\mathrm{V}$, confirming the presence of a highly activated bound dinitrogen, reduced to a hydrazido group $\left(\mathrm{N}_{2}{ }^{4-}\right)$.

These results show that the two uranium(III) ions, held together by a potassium-bound oxo ligand in a multimetallic $\mathrm{K}_{2} \mathrm{UOU}$ core, are able to bind dinitrogen and to effect its four-electron reduction, as previously reported for the nitride-bridged $\mathrm{K}_{3} \mathrm{UN}\left(\mathrm{N}_{2}\right) \mathrm{U}\left(\right.$ ref. $\left.^{8}\right)$ in spite of the lower electron-rich character of the uranium cations in the oxo complex (as a result of the replacement of $\mathrm{N}^{3-}$ by $\mathrm{O}^{2-}$ ). Such a remarkable reactivity is only the second example ${ }^{8}$ of four-electron reduction of dinitrogen by a uranium complex and indicates that the oxo group also provides a versatile linker for the assembly of highly reactive multimetallic uranium complexes.

To understand how the replacement of the nitride group in $\mathrm{K}_{3} \mathrm{UN}\left(\mathrm{N}_{2}\right) \mathrm{U}$ by an oxo group in $4,\left(\mathrm{~K}_{2} \mathrm{UO}\left(\mathrm{N}_{2}\right) \mathrm{U}\right)$, affects the reactivity of the bound dinitrogen, we investigated the reaction of 4 with $\mathrm{CO}, \mathrm{H}_{2}$ and $\mathrm{H}^{+}$. When a toluene solution of complex 4 is exposed to 3 equiv. of $\mathrm{CO}$, the reaction mixture immediately changes colour from dark brown to dark purple. Black crystals of the cyanamidobridged complex $\left[\mathrm{K}_{2}\left\{\left[\mathrm{U}\left(\mathrm{OSi}\left(\mathrm{O}^{t} \mathrm{Bu}\right)_{3}\right)_{3}\right]_{2}(\mu-\mathrm{O})_{2}(\mu-\mathrm{NCN})\right\}\right]$ (5) were isolated from a toluene solution at $-40^{\circ} \mathrm{C}$ with $68 \%$ yield. The infrared spectrum of the isolated compound $\mathbf{5}$ shows a strong vibration at $2,008 \mathrm{~cm}^{-1}$, assigned to the $\mathrm{NCN}^{2-}$ ligand, which is shifted to $1,942 \mathrm{~cm}^{-1}$ for the ${ }^{13} \mathrm{C}$-labelled complex ${ }^{13} \mathrm{C}-5$ (Supplementary Figs. 49 and 50). These values are in the range of those reported $\left(1,975-2,061 \mathrm{~cm}^{-1}\right)^{35,36}$ in metal complexes of the cyanamide ligand, and compare well to the value reported for a cyanamide-bridged diuranium(IV) complex $\left(2,034 \mathrm{~cm}^{-1}\right)$ where the ligand adopts a linear $\mu-\eta^{1}-\kappa^{1} \mathrm{~N}-\kappa^{1} \mathrm{~N}^{\prime}$ binding mode ${ }^{37}$.

In this unique reaction, both the dinitrogen single bond and the $\mathrm{CO}$ triple bond are cleaved at room temperature to afford a bridging oxo group and a bridging cyanamide ligand $\left(\mathrm{NCN}^{2-}\right)$, leaving the oxidation state of the uranium atoms unchanged. The reactivity displayed by the oxo-hydrazido complex $\mathbf{4}$ differs completely from that observed for other reported hydrazido complexes ${ }^{7}$ and in particular from that of the nitrido-hydrazido and imido-hydrazido uranium(v) complexes $\mathrm{K}_{3} \mathrm{UN}\left(\mathrm{N}_{2}\right) \mathrm{U}$ and $\mathrm{K}_{2} \mathrm{U}_{2}(\mathrm{NH})\left(\mathrm{N}_{2}\right)$ ], respectively $^{8}$. Notably the reaction of the $\mathrm{U}(\mathrm{v})$ complexes $\left[\mathrm{K}_{3} \mathrm{U}_{2} \mathrm{~N}\left(\mathrm{~N}_{2}\right)\right]$ and $\left[\mathrm{K}_{2} \mathrm{U}_{2}(\mathrm{NH})\left(\mathrm{N}_{2}\right)\right]$ with $\mathrm{CO}(3-10$ equiv.) resulted in the reductive carbonylation of the hydrazido ligand, leading to formation of $\mathrm{U}(\mathrm{IV}) \mathrm{U}(\mathrm{IV})$ bis-cyanate and U(III)U(IV) mono-cyanate complexes, respectively ${ }^{8}$. The reactivity of $\mathbf{4}$ with $\mathrm{CO}$ also differs from that observed for group 4 dinitrogen complexes. Notably the addition of $\mathrm{CO}$ to hydrazido complexes of $\mathrm{Hf}(\mathrm{IV})$ results in the addition of two CO molecules to the $\mathrm{Hf}$ (Iv)-bound $\mathrm{N}_{2}{ }^{4-}$ group and the formation of an oxamidide $\left(\left[\mathrm{N}_{2} \mathrm{C}_{2} \mathrm{O}_{2}\right]^{4-}\right)$ bridged $\mathrm{Hf}(\mathrm{IV})$ complex ${ }^{7}$.

This novel reactivity suggests that reduction of the uranium centres is less accessible in complex $\mathbf{4}$ compared to the nitride analogue, but that the strong nucleophilic character of the bound $\mathrm{N}_{2}{ }^{4-}$ group still allows the concomitant cleavage of the $\mathrm{CO}$ and $\mathrm{N}_{2}$ bonds.

However, the addition of excess CO (10-100 equiv.) to the isolated cyanamide complex 5 results in the slow transformation of 

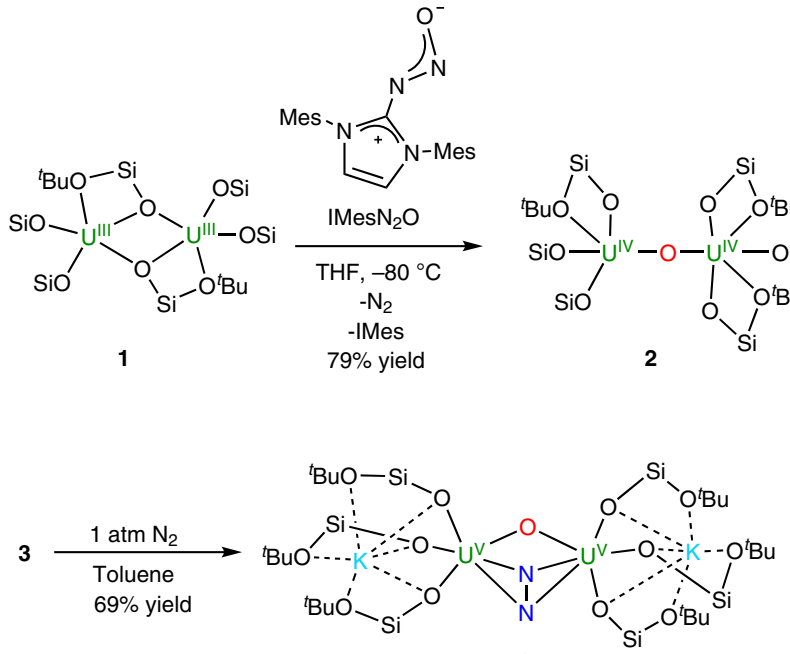

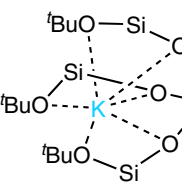

4

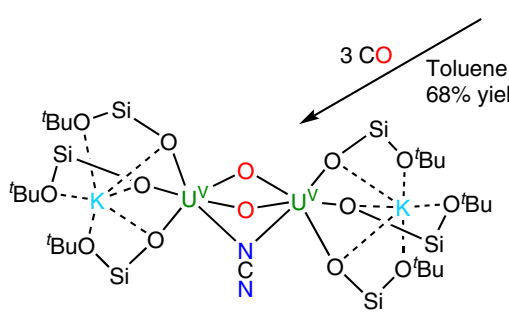

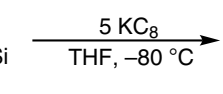

$40 \%$ yield

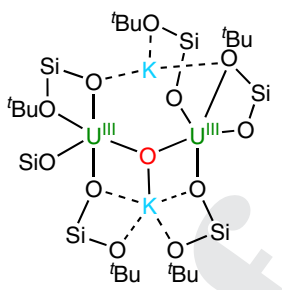

3

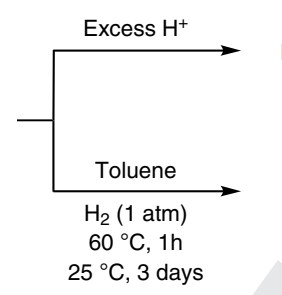

$\mathrm{N}_{2}$

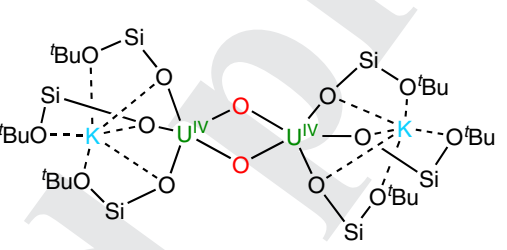

6

Fig. 2 | Synthesis and reactivity of oxo-bridged diuranium complexes. The reaction of $\mathbf{1}$ with IMes $\mathrm{N}_{2} \mathrm{O}$ affords the diuranium(IV) oxo-bridged complex 2. The reduction of $\mathbf{2}$ with excess of $\mathrm{KC}_{8}$ affords the diuranium(III) oxo-bridged complex $\mathbf{3}$. Complex $\mathbf{3}$ reacts with 1 atm $\mathrm{N}_{2}$ to afford the hydrazido complex $\mathbf{4}$, then $\mathbf{4}$ reacts in ambient conditions with $\mathrm{CO}$ to afford the cyanamido-bridged complex $\mathbf{5}$ and with $\mathrm{H}_{2}$ to afford $\mathrm{N}_{2}$ and hydride complex $\mathbf{7}$. Then, $\mathbf{5}$ reacts with excess $\mathrm{CO}$ to afford the bis-oxo complex 6 . In all complexes, only the - $\mathrm{O}^{t} \mathrm{Bu}$ groups of the $\mathrm{OSi}\left(\mathrm{O}^{t} \mathrm{Bu}\right)_{3}$ that are metal bound are shown.

5 (3 days when 18 equiv. are used) into the bis-oxo diuranium(IV) complex $\left[\mathrm{K}_{2}\left\{\left[\mathrm{U}\left(\mathrm{OSi}\left(\mathrm{O}^{t} \mathrm{Bu}\right)_{3}\right)_{3}\right]_{2}(\mu-\mathrm{O})_{2}\right\}\right] \mathbf{6}$ with a conversion rate of $85 \%$. The reduction of the uranium cations is accompanied by the elimination of the product of $\mathrm{CO}$ addition to the cyanamide, which could not be identified.

The reaction of a toluene solution of complex 4 with excess acid $\left(\mathrm{HCl}\left(\mathrm{Et}_{2} \mathrm{O}\right)\right.$ or $\left.\mathrm{HBAr}_{4}^{\mathrm{F}}\right)$ alone or in the presence of a reducing agent $\left(\mathrm{KC}_{8}\right)$ did not result in the formation of ammonia, as previously observed following the addition of excess acid to $\mathrm{K}_{3} \mathrm{UN}\left(\mathrm{N}_{2}\right) \mathrm{U}$ (Fig. 1), but instead in the elimination of $\mathrm{N}_{2}$. A dramatic difference in reactivity between 4 and $\mathrm{K}_{3} \mathrm{UN}\left(\mathrm{N}_{2}\right) \mathrm{U}$ was also observed on adding $\mathrm{H}_{2}$. The reaction of a toluene solution of complex 4 with $1 \mathrm{~atm}$ of $\mathrm{H}_{2}$ for three days at room temperature or $1 \mathrm{~h}$ at $60^{\circ} \mathrm{Cled}$ to the quantitative conversion of 4 into a new species, as indicated by ${ }^{1} \mathrm{H}$ NMR studies (Supplementary Figs. 32-37), showing a signal at $11.96 \mathrm{ppm}$ integrating for two protons. The latter can be assigned to the protons derived from $\mathrm{H}_{2}$, because the peak disappears when the reaction is carried out with $\mathrm{D}_{2}$. Gas chromatography-mass spectrometry of the headspace of the reaction mixture showed that evolution of $\mathrm{N}_{2}$ had occurred during the reaction. A yellow solid could be isolated from this reaction, and elemental analysis did not show the presence of nitrogen. Furthermore, even in the presence of a reducing agent, the addition of excess acid $\left(\mathrm{HCl}\left(\mathrm{Et}_{2} \mathrm{O}\right)\right)$ to the product of the reaction of 4 with $\mathrm{H}_{2}$ did not result in the formation of nitrogencontaining products. The recorded data indicate that addition of $\mathrm{H}_{2}$ to 4 leads to the elimination of $\mathrm{N}_{2}$ and suggest the formation of a diuranium(IV) oxo bis-hydride complex $\left(\left[\mathrm{K}_{2}\left\{\left[\mathrm{U}\left(\mathrm{OSi}\left(\mathrm{O}^{t} \mathrm{Bu}\right)_{3}\right)_{3}\right]_{2}(\mu\right.\right.\right.$ $-\mathrm{O})(\mathrm{H})(\mathrm{H})]\}], 7)$. The magnetic data measured for complex 7 are in agreement with the presence of $\mathrm{U}(\mathrm{IV})^{38}$. The same compound was also obtained from the reaction of the U(III) oxo complex 3 with 1 atm $\mathrm{H}_{2}$. Examples of $\mathrm{N}_{2}$ elimination following dihydrogen addi- tion have been reported ${ }^{2,39}$ and are usually indicative of a low degree of activation of the bound dinitrogen.

Thus, the reactivity of the oxo-bridged $\mathrm{K}_{2} \mathrm{UO}\left(\mathrm{N}_{2}\right) \mathrm{U}$ dinitrogen complex differs dramatically from that of the nitride-bridged $\mathrm{K}_{2} \mathrm{UO}\left(\mathrm{N}_{2}\right) \mathrm{U}$ complex, which reacts with $\mathrm{H}_{2}$ and acid to produce ammonia almost quantitatively (77\% conversion of the nitrido and hydrazido groups into ammonia). The difference is probably due both to structural effects arising from differences in the alkali ion binding mode and to differences in the electronic structures of the two complexes. Dramatic differences in the reactivity of analogous $\mathrm{N}_{2}$ bound complexes with $\mathrm{H}_{2}$ have been reported following subtle changes of the supporting ligand (from $\eta^{5}-\mathrm{C}_{5} \mathrm{Me}_{5}$ to $\eta^{5}-\mathrm{C}_{5} \mathrm{Me}_{4}-\mathrm{H}$ ) but in that case the change in supporting ligand led to a different binding mode of the dinitrogen (end-on versus side-on) as result of steric protection by the ligand. In contrast the subtle change from nitride to oxide does not lead to significant steric changes and results in the same binding mode (side-on) and the same degree of reduction of the bound dinitrogen.

Solid-state structures. The solid-state structures of compounds $\mathbf{2}$, 3, 4, 5 and 6 were determined by X-ray crystallography (Fig. 3; the structure of $\mathbf{6}$ is provided in Supplementary Fig. 52). In complex 2 , an oxo ligand $\left(\mathrm{O}^{2-}\right)$ bridges, with an angle that deviates slightly from linearity (172.19(7) $\AA$; U...U 4.2129(9) $\AA$ ), two inequivalent $\mathrm{U}(\mathrm{IV})$ centres. The values of the U(Iv)-oxo distances (2.0852(13) and 2.1376(13) $\AA$ ) fall in the range of those found in analogous oxobridged diuranium(IV) complexes $(2.0881(4)-2.147(6) \AA)^{20,22,24,27,2}$ $9,30,40$. The structure of 3 shows the presence of a neutral complex with two U(III) ions bridged by an oxo ligand that is also bound to a potassium cation located in the pocket formed by four oxygen atoms of the siloxide ligands $(\mathrm{K} 2-\mathrm{O} 121=2.913(4) \AA)$. A second 

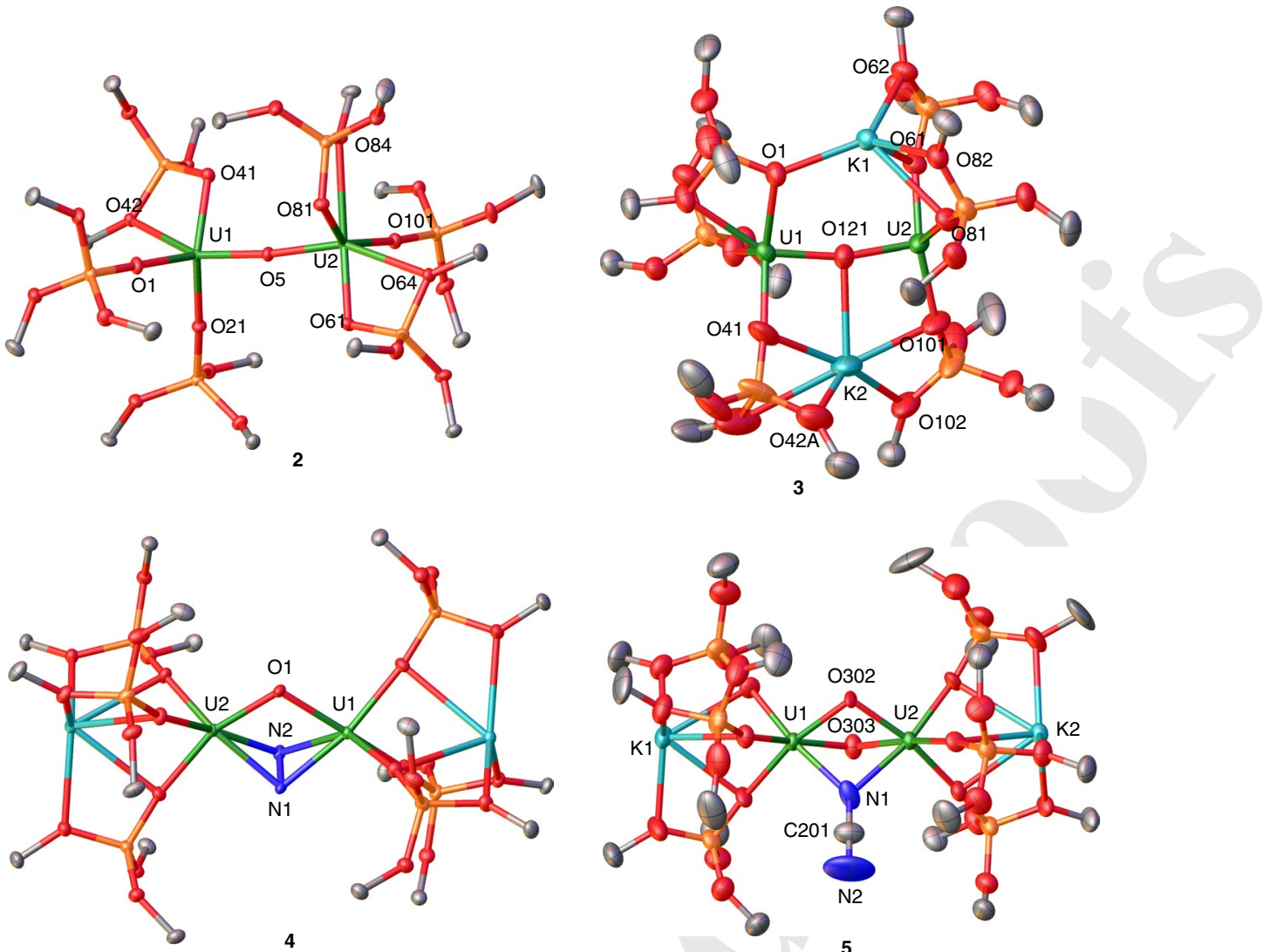

Fig. 3| Molecular structure of 2, 3, 4 and 5. Thermal ellipsoids depicted at 50\% probability. Hydrogen atoms and methyl groups are omitted for clarity.

potassium cation is coordinated by the oxygen atoms of the siloxide ligands at a non-bonding distance from the oxo group (K1$\mathrm{O} 121=3.392(4) \AA)$. The values of the $\mathrm{U}(\mathrm{III})-$ oxo bond distances (2.178(4) and 2.109(4) $\AA$ ) are significantly longer than those found for 2 (2.0852(13) and 2.1376(13) $\mathrm{A}$ ) and compare well with those found in the only other crystallographically characterized oxobridged diuranium(III) complexes. (2.125(13) and 2.094(14) $\AA)^{18}$. In complex 3 , the two uranium atoms are maintained in close proximity at a U...U distance of $4.2619(5) \AA$ by the oxo group and by the metallo-ligand framework formed by the potassium-bound siloxides. This distance is slightly longer than that found in the nitride-bridged diuranium(III) complex $\left[\mathrm{K}_{3}\left\{\left[\mathrm{U}\left(\mathrm{OSi}\left(\mathrm{O}^{t} \mathrm{Bu}\right)_{3}\right)_{3}\right]_{2}(\mu\right.\right.$ -N)\}] $\left(\mathrm{K}_{3} \mathrm{UNU} \text {; } 4.234(2) \AA\right)^{8}$. The U-O-U core $\left(167.4(2)^{\circ}\right)$ in 3 is significantly more bent than that of the $\mathrm{U}-\mathrm{N}-\mathrm{U}$ core in the $\mathrm{K}_{3} \mathrm{UNU}$ complex $\left(173.7(8)^{\circ}\right)$.

The structure of 4 reveals the presence of one oxo group $\left(\mathrm{U}-\mathrm{O}-\mathrm{U}=105.0(3) \AA\right.$ and a side-on $\left(\mathrm{U} 1-\mathrm{N} 1 \mathrm{~A}-\mathrm{U} 2=99.0(2)^{\circ}\right.$ and $\left.\mathrm{U} 1-\mathrm{N} 2 \mathrm{~A}-\mathrm{U} 2=98.56(18)^{\circ}\right)$ bound hydrazido moiety $\left(\mathrm{N}_{2}{ }^{4-}\right)$ bridging two uranium $(\mathrm{v})$ centres in a diamond-shaped geometry with a short U...U distance of $(3.3801(5) \AA)$. Unlike the previously reported $\mathrm{U}(\mathrm{v})$ nitrido-hydrazido complex $\left[\mathrm{K}_{3}\left\{\left[\mathrm{U}\left(\mathrm{OSi}\left(\mathrm{O}^{t} \mathrm{Bu}\right)_{3}\right)_{3}\right]_{2}(\mu\right.\right.$ $\left.\left.-\mathrm{N})\left(\mu-\mathrm{N}_{2}\right)\right\}\right]\left(\mathrm{K}_{3} \mathrm{UN}\left(\mathrm{N}_{2}\right) \mathrm{U}\right)$ in which three potassium cations were bound to the nitrido and hydrazido groups in the core of the molecule (U...U distance of 3.3052(5) $\AA$ ), in 4 the two potassium cations are located in the pockets formed by the siloxide ligands and do not bind the core $\mathrm{N}, \mathrm{N}$ and $\mathrm{O}$ atoms. The $\mathrm{U}_{2}\left(\mu-\eta^{2}-\mathrm{N}_{2}\right)$ moiety in 4 features U-N bond distances ranging from 2.279(8) to 2.157(17) $\AA$ that are comparable to those found in $\mathrm{K}_{3} \mathrm{UN}\left(\mathrm{N}_{2}\right) \mathrm{U}$ (2.311(13)2.163(13) $\AA$ ). The N-N bond length in complex $4(1.40(1) \AA)$ is comparable to the observed bond length in hydrazine, $\mathrm{H}_{2} \mathrm{NNH}_{2}$ $(1.47 \AA)$, and falls in the range of values $(1.377-1.548 \AA)$ reported for hydrazido complexes of $\mathrm{Zr}(\mathrm{IV})$ and $\mathrm{U}(\mathrm{v})^{3,4,41,42}$.
The structure of complex 5 shows a dinuclear complex in which each uranium atom is coordinated by three siloxide ligands, two bridging oxo groups and a cyanamido $\left(\mathrm{N} \equiv \mathrm{C}-\mathrm{N}^{2-}\right)$ ligand adopting a $\mu-\kappa \mathrm{N}, \kappa \mathrm{N}$ bridging mode. The observed $\mathrm{C}-\mathrm{N}$ bond distances in 5 are in agreement with the presence of a cyanamido $\left(\mathrm{N} \equiv \mathrm{C}_{-} \mathrm{N}^{2-}\right)$ ligand $(\mathrm{N} 1-\mathrm{C} 201=1.302(17) \AA$ and $\mathrm{C} 201-\mathrm{N} 2=1.23(2) \AA)$ and are in good agreement with those found in previously reported metal complexes containing the bridging cyanamido ligand ${ }^{35,37,43}$.

The structure of $\mathbf{6}$ shows the presence of two uranium(IV) cations bridged by two oxo groups. The U-O distances of 2.092(5)2.182(5) $\AA$ are comparable to those reported in analogous U(IV) bis-oxo diuranium complexes ${ }^{44,45}$.

Magnetic data. To further investigate differences in the electronic structures of the oxo and nitride complexes that may be responsible for the differences in reactivity, we carried out magnetic studies. The two dinuclear complexes ( 3 and $\mathrm{K}_{3} \mathrm{UNU}$ ) have a similar magnetic moment ( $\mu=2.10 \mu_{\mathrm{B}}$ for 3 and $\mu=2.04 \mu_{\mathrm{B}}$ for K3UNU) at room temperature, in agreement with the presence of uranium(III) ions ${ }^{38}$, but show remarkably different magnetic behaviour, as is clearly observable in the plots of the magnetic susceptibility $(\chi)$ versus $T$ and $\chi T$ versus $T$ (Fig. 4 ). The $\chi$ versus $T$ plot for nitride complex $\mathrm{K}_{3} \mathrm{UNU}$ exhibits the magnetic behaviour of an antiferromagnetically coupled dinuclear complex with a maximum at $23 \mathrm{~K}$. In contrast, the $\chi$ versus $T$ plot for 3 shows the magnetic behaviour of two magnetically independent U(III) ions. Similarly, the dinuclear dinitrogen complexes 4 and $\mathrm{K}_{3} \mathrm{UN}\left(\mathrm{N}_{2}\right) \mathrm{U}$ have a similar magnetic moment ( $\mu=1.75 \mu_{\mathrm{B}}$ for 4 and $\mu=1.80 \mu_{\mathrm{B}}$ for K3UN(N2)U), indicative of the presence of $\mathrm{U}(V)$ cations, but show different $\chi$ versus $T$ plots suggestive of the presence of two magnetically independent ions in $\mathbf{4}$ and of an antiferromagnetically coupled system for the nitride complex (Fig. 4). These results suggest that the nitride ligand 

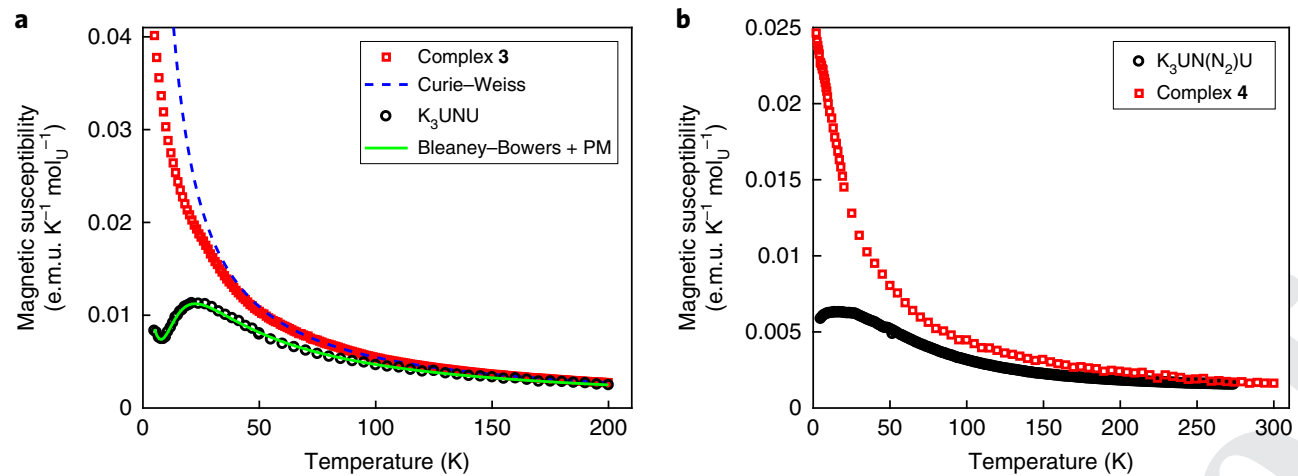

Fig. 4 | Magnetic susceptibility. a,b, Comparison of the variable-temperature magnetic susceptibility of 3 versus $K_{3} U N U(\mathbf{a})$ and of 4 versus $K_{3} U N\left(N_{2}\right) U(\mathbf{b})$.
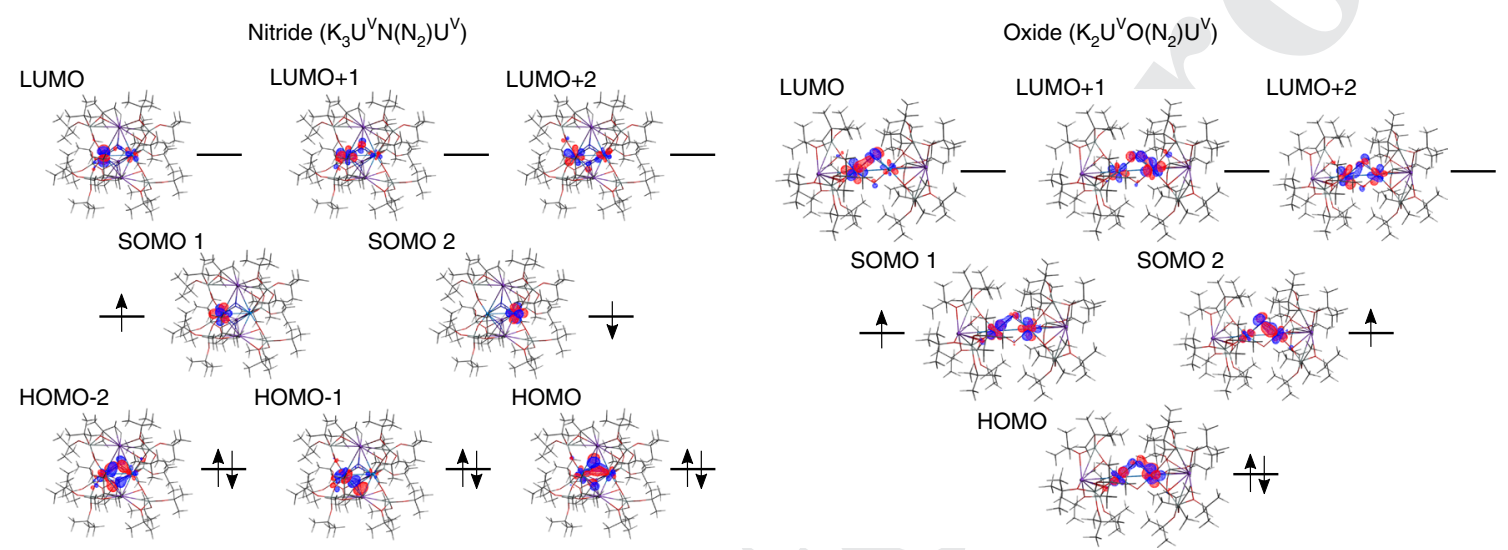

Fig. 5 | Molecular orbitals of the different complexes. Molecular orbitals of the $K_{3} U N U$ (top left), $K_{2} \cup O U$ (top right), $K_{3} \cup N\left(N_{2}\right) \cup($ bottom left) and $\mathrm{K}_{2} \mathrm{UO}\left(\mathrm{N}_{2}\right) \mathrm{U}$ (bottom right) complexes. Orbital overlap is present in $\mathrm{K}_{3} \mathrm{UNU}$ and $\mathrm{K}_{3} \mathrm{UN}\left(\mathrm{N}_{2}\right) \mathrm{U}$ (covalent character), but not in $\mathrm{K}_{2} \mathrm{UOU}$ and $\mathrm{K}_{2} \mathrm{UO}\left(\mathrm{N}_{2}\right) \mathrm{U}$ (ionic character). SOMO, singly occupied molecular orbital; HOMO, highest occupied molecular orbital; LUMO, lower unoccupied molecular orbital.

allows for a better communication between the metal centres compared to the oxide.

Computational analysis. In agreement with the magnetic data, density functional theory (DFT) level computations indicate that the singlet, antiferromagnetic state is the most stable at $0 \mathrm{~K}$ for the nitride complex, while the triplet, paramagnetic state is the most stable for 3 (Supplementary Table 3). As shown in Fig. 5 the frontier orbitals (HOMO-5 to LUMO+2) of the $\mathrm{K}_{3} \mathrm{U}^{\mathrm{III}} \mathrm{NU}^{\mathrm{III}}$ complex suggest a markedly covalent character of the $\mathrm{U}-\mathrm{N}-\mathrm{U}$ bond. On the other hand, no orbital overlap exists in 3 between the bridging oxide $\left(\mathrm{O}^{2-}\right)$ and the two uranium centres, which would suggest a strictly ionic type of bonding. Topological analysis of the electron density about the bonds with the bridging atom further supports the difference in bonding character (Supplementary Fig. 58).

The bond character and spin state of each complex do not change on complexation of the $\mathrm{N}_{2}$ substrate. In particular, orbital overlap persists in the nitride case (covalent), but it does not appear in the oxide complex (ionic). As shown in Fig. 5, this affects the binding of the $\mathrm{N}_{2}$ substrate, resulting in significant differences between the two complexes. In the case of $\mathrm{K}_{3} \mathrm{UN}\left(\mathrm{N}_{2}\right) \mathrm{U}$, both uranium atoms and both nitrogen atoms from dinitrogen are involved in bonding, while in $\mathrm{K}_{2} \mathrm{UO}\left(\mathrm{N}_{2}\right) \mathrm{U}$ the overlap is asymmetric, involving only one uranium atom. Moreover, all $\mathrm{N}_{2}$ bonding orbitals present a strong component centred on the bridging nitride ligand atom, but none centred on oxygen. Natural bond order analysis and the Wiberg bond index indicate that this results in a decreased $\mathrm{N}-\mathrm{N}$ bond order (1.4 in 4 and 1.0 in $\mathrm{K}_{3} \mathrm{UN}\left(\mathrm{N}_{2}\right) \mathrm{U}$ ) and an increased $\mathrm{U}-\mathrm{N}\left(\mathrm{N}_{2}\right)$ bond order in the nitride complex compared to the oxide one. This observation suggests that the bridging nitride does participate in the binding and consequent activation of $\mathrm{N}_{2}$, while the oxide does not. Combined together, the asymmetric orbital overlap and the spectator role of the bridging oxygen provide a theoretical basis to rationalize the striking difference in reactivity of the $\mathrm{N}_{2}$ substrate in the nitride and oxo complexes.

\section{Conclusion}

In summary, we have shown that bridging oxo groups can be used to support uranium in a low oxidation state in affording multimetallic complexes that effect the reduction and functionalization of dinitrogen. The uranium-bound dinitrogen is easily cleaved in ambient conditions by $\mathrm{CO}$, affording an original compound via $\mathrm{N}-\mathrm{C}$ bond formation. This provides a route for building organonitrogen compounds from cheap resources (notably cyanamide is formed from $\mathrm{CO}$ and $\mathrm{N}_{2}$ ). We demonstrate that the substitution of a nitride linker with an oxo linker has dramatic effects on the reactivity of the resulting multimetallic uranium(III) complex towards dinitrogen. Specifically, the presence of the oxo linker results in the release of dinitrogen following the addition of dihydrogen, while the subsequent addition of hydrogen and acid to the nitride complex leads to ammonia formation. Moreover, the oxo linker leads to unusual reactivity of the uranium-bound dinitrogen as a result of structural and electronic differences compared to the nitride-linked diuranium complex. Thus, the results show that both oxo groups and nitride groups can be used as linkers to build low-valent multimetallic complexes for dinitrogen reduction, and on the other hand 
they show that the nature of the linker dramatically affects the reactivity of the bound dinitrogen. DFT computations and magnetic data indicate a different bonding scheme for the nitride and oxide complexes with a markedly covalent character of the $\mathrm{U}-\mathrm{N}-\mathrm{U}$ bond and a strictly ionic $\mathrm{U}-\mathrm{O}-\mathrm{U}$ bond. This difference is maintained in the respective dinitrogen complexes where the bridging nitride also participates in the binding and consequent activation of $\mathrm{N}_{2}$, while the oxide does not. These results show that, in spite of the presence of the same dinitrogen binding mode, the same supporting ligands and the same oxidation level of the metal centres, the nature of the linker has a significant impact on the degree of $\mathrm{N}_{2}$ activation.

\section{Data availability}

All data generated and analysed during this study are included in this Article and its Supplementary Information or are available from the corresponding author upon reasonable request. Atomic coordinates and structure factors for the reported crystal structures have been deposited in the Cambridge Crystallographic Data Centre under accession codes CCDC 1821630 (2), 1821631 (3), 1821633 (4), $1821634(5)$ and $1821632(6)$

Received: 8 February 2018; Accepted: 3 October 2018; (1)

\section{References}

1. Burford, R. J. \& Fryzuk, M. D. Examining the relationship between coordination mode and reactivity of dinitrogen. Nat. Rev. Chem. 1, (2017).

2. Shaver, M. P. \& Fryzuk, M. D. Activation of molecular nitrogen: coordination, cleavage and functionalization of $\mathrm{N}_{2}$ mediated by metal complexes. Adv. Synth. Catal. 345, 1061-1076 (2003).

3. Pool, J. A., Lobkovsky, E. \& Chirik, P. J. Hydrogenation and cleavage of dinitrogen to ammonia with a zirconium complex. Nature 427, 527-530 (2004)

4. Fryzuk, M. D., Love, J. B., Rettig, S. J. \& Young, V. G. Transformation of coordinated dinitrogen by reaction with dihydrogen and primary silanes. Science 275, 1445-1447 (1997).

5. Wang, B. L. et al. Dinitrogen activation by dihydrogen and a PNP-ligated titanium complex. J. Am. Chem. Soc. 139, 1818-1821 (2017).

6. Keane, A. J., Farrell, W. S., Yonke, B. L., Zavalij, P. Y. \& Sita, L. R. Metalmediated production of isocyanates, $\mathrm{R}_{3} \mathrm{EN}=\mathrm{C}=\mathrm{O}$ from dinitrogen, carbon dioxide, and $\mathrm{R}_{3} \mathrm{ECl}$. Angew. Chem. Int. Ed. 54, 10220-10224 (2015).

7. Knobloch, D. J., Lobkovsky, E. \& Chirik, P. J. Dinitrogen cleavage and functionalization by carbon monoxide promoted by a hafnium complex. Nat. Chem. 2, 30-35 (2010)

8. Falcone, M., Chatelain, L., Scopelliti, R., Zivkovic, I. \& Mazzanti, M. Nitrogen reduction and functionalization by a multimetallic uranium nitride complex. Nature 547, 332-335 (2017)

9. Anderson, J. S., Rittle, J. \& Peters, J. C. Catalytic conversion of nitrogen to ammonia by an iron model complex. Nature 501, 84-87 (2013).

10. Yandulov, D. V. \& Schrock, R. R. Catalytic reduction of dinitrogen to ammonia at a single molybdenum center. Science 301, 76-78 (2003).

11. MacLeod, K. C. \& Holland, P. L. Recent developments in the homogeneous reduction of dinitrogen by molybdenum and iron. Nat. Chem. $\mathbf{5}$, 559-565 (2013).

12. Haber, F. Verfahren zur Herstellung von Ammoniak durch katalytische Vereinigung von Stickstoff und Wasserstoff, zweckmäßig unter hohem Druch. German patent DE 229126 (1909).

13. Cloke, G. F. N. \& Hitchcock, P. B. Reversible binding and reduction of dinitrogen by a uranium (III) pentalene complex. J. Am. Chem. Soc. 124, 9352-9353 (2002).

14. Odom, A. L., Arnold, P. L. \& Cummins, C. C. Heterodinuclear uranium/ molybdenum dinitrogen complexes. J. Am. Chem. Soc. 120, 5836-5837 (1998).

15. Mansell, S. M., Kaltsoyannis, N. \& Arnold, P. L. Small molecule activation by uranium tris(aryloxides): experimental and computational studies of binding of $\mathrm{N}_{2}$, coupling of $\mathrm{CO}$, and deoxygenation insertion of $\mathrm{CO}_{2}$ under ambient conditions. J. Am. Chem. Soc. 133, 9036-9051 (2011).

16. Evans, W. J., Kozimor, S. A. \& Ziller, J. W. A monometallic f element complex of dinitrogen: $\left(\mathrm{C}_{5} \mathrm{Me}_{5}\right)_{3} \mathrm{U}\left(\eta^{1}-\mathrm{N}_{2}\right)$. J. Am. Chem. Soc. 125, 14264-14265 (2003).

17. Roussel, P. \& Scott, P. Complex of dinitrogen with trivalent uranium. J. Am. Chem. Soc. 120, 1070-1071 (1998).

18. Evans, W. J., Kozimor, S. A. \& Ziller, J. W. Bis(pentamethylcyclopentadienyl) $\mathrm{U}(\mathrm{III})$ oxide and U(IV) oxide carbene complexes. Polyhedron 23, 2689-2694 (2004).

19. Larch, C. P., Cloke, F. G. N. \& Hitchcock, P. B. Activation and reduction of diethyl ether by low valent uranium: formation of the trimetallic, mixed valence uranium oxo species $\left[\mathrm{U}\left(\mathrm{Cp}^{\mathrm{RR}}\right)(\mu-\mathrm{I})_{2}\right]_{3}\left(\mu_{3}-\mathrm{O}\right)\left(\mathrm{Cp}^{\mathrm{RR}}=\mathrm{C}_{5} \mathrm{Me}_{5}, \mathrm{C}_{5} \mathrm{Me}_{4} \mathrm{H}\right.$, $\left.\mathrm{C}_{5} \mathrm{H}_{4} \mathrm{SiMe}_{3}\right)$. Chem. Commun. 82-84 (2008).
20. Castro-Rodriguez, I., Olsen, K., Gantzel, P. \& Meyer, K. Uranium complexes supported by an aryloxide functionalised triazacyclononane macrocycle: synthesis and characterisation of a six-coordinate U(III) species and insights into its reactivity. Chem. Commun. 2764-2765 (2002).

21. Wang, J. X., Gurevich, Y., Botoshansky, M. \& Eisen, M. S. Unique $\sigma$-bond metathesis of silylalkynes promoted by an ansa-dimethylsilyl and oxo-bridged uranium metallocene. J. Am. Chem. Soc. 128, 9350-9351 (2006).

22. Lam, O. P., Bart, S. C., Kameo, H., Heinemann, F. W. \& Meyer, K. Insights into the mechanism of carbonate formation through reductive cleavage of carbon dioxide with low-valent uranium centers. Chem. Commun. 46, 3137-3139 (2010).

23. Castro, L., Lam, O. P., Bart, S. C., Meyer, K. \& Maron, L. Carbonate formation from $\mathrm{CO}_{2}$ via oxo versus oxalate pathway: theoretical investigations into the mechanism of uranium-mediated carbonate formation. Organometallics. 29, 5504-5510 (2010).

24. Fortier, S., Brown, J. L., Kaltsoyannis, N., Wu, G. \& Hayton, T. W. Synthesis, molecular and electronic structure of $\mathrm{UV}(\mathrm{O})\left[\mathrm{N}\left(\mathrm{SiMe}_{3}\right)_{2}\right]_{3}$. Inorg. Chem. 51, 1625-1633 (2012).

25. Berthet, J. C. et al. Synthesis and crystal structure of the oxo-bridged bimetallic organouranium complex $\left[\left\{\left(\mathrm{Me}_{3} \mathrm{SiC}_{5} \mathrm{H}_{4}\right)_{3} \mathrm{U}_{2}\right\} \mu-\mathrm{O}\right]$. J. Organomet. Chem. 408, 335-341 (1991).

26. Schmidt, A. C., Nizovtsev, A. V., Scheurer, A., Heinemann, F. W. \& Meyer, K. Uranium-mediated reductive conversion of $\mathrm{CO}_{2}$ to $\mathrm{CO}$ and carbonate in a single-vessel, closed synthetic cycle. Chem. Commun. 48, 8634-8636 (2012).

27. Frey, A. S. P., Cloke, F. G. N., Coles, M. P. \& Hitchcock, P. B. U'III-induced reductive co-coupling of $\mathrm{NO}$ and $\mathrm{CO}$ to form $\mathrm{U}(\mathrm{IV})$ cyanate and oxo derivates. Chem. Eur. J. 16, 9446-9448 (2010).

28. Avens, L. R., Barnhart, D. M., Burns, C. J., McKee, S. D. \& Smith, W. H. Oxidation chemistry of a U(III) aryloxide. Inorg. Chem. 33, 4245-4254 (1994).

29. Falcone, M., Kefalidis, C. E., Scopelliti, R., Maron, L. \& Mazzanti, M. Facile $\mathrm{CO}$ cleavage by a multimetallic $\mathrm{CsU}_{2}$ nitride complex. Angew. Chem. Int. Ed. 55, 12290-12294 (2016).

30. Falcone, M., Chatelain, L. \& Mazzanti, M. Nucleophilic reactivity of a nitride-bridged diuranium(Iv) complex: $\mathrm{CO}_{2}$ and $\mathrm{CS}_{2}$ functionalization. Angew. Chem. Int. Ed. 55, 4074-4078 (2016).

31. Mougel, V. et al. Siloxides as supporting ligands in uranium(III)-mediated small-molecule activation. Angew. Chem. Int. Ed. 51, 12280-12284 (2012).

32. Tskhovrebov, A. G., Vuichoud, B., Solari, E., Scopelliti, R. \& Severin, K. Adducts of nitrous oxide and $N$-heterocyclic carbenes: syntheses, structures, and reactivity. J. Am. Chem. Soc. 135, 9486-9492 (2013).

33. Tskhovrebov, A. G., Solari, E., Wodrich, M. D., Scopelliti, R. \& Severin, K. Covalent capture of nitrous oxide by $\mathrm{N}$-heterocyclic carbenes. Angew. Chem. Int. Ed. 51, 232-234 (2012).

34. Palluccio, T. D. et al. Thermodynamic and kinetic study of cleavage of the $\mathrm{N}-\mathrm{O}$ bond of $\mathrm{N}$-oxides by a vanadium(III) complex: enhanced oxygen atom transfer reaction rates for adducts of nitrous oxide and mesityl nitrile oxide. J. Am. Chem. Soc. 135, 11357-11372 (2013).

35. Huynh, M. H. V., White, P. S., Carter, C. A. \& Meyer, T. J. Formation and reactivity of the osmium(Iv)-cyanoimido complex $\mathrm{Os}^{\mathrm{IV}}(\mathrm{bpy})(\mathrm{Cl})_{3}(\mathrm{NCN})^{-}$. Angew. Chem. Int. Ed. 40, 3037-3039 (2001).

36. Kajitani, H., Tanabe, Y., Kuwata, S., Iwasaki, M. \& Ishii, Y. A cyanamidobridged diiridium complex: a reactive building block for polynuclear cyanamido complexes. Organometallics. 24, 2251-2254 (2005).

37. Mindiola, D. J. et al. Bimetallic $\mu$-cyanoimide complexes prepared by NCN group transfer. Chem. Commun. 125-126 (2001).

38. Kindra, D. R. \& Evans, W. J. Magnetic susceptibility of uranium complexes. Chem. Rev. 114, 8865-8882 (2014).

39. Pool, J. A., Bernskoetter, W. H. \& Chirik, P. J. On the origin of dinitrogen hydrogenation promoted by $\left[\left(\eta^{5}-\mathrm{C}_{5} \mathrm{Me}_{4} \mathrm{H}\right)_{2} \mathrm{Zr}\right]_{2}\left(\mu_{2}, \eta^{2}, \eta^{2}-\mathrm{N}_{2}\right)$. J. Am. Chem. Soc. 126, 14326-14327 (2004).

40. La Pierre, H. S. \& Meyer, K. in Progress in Inorganic Chemistry Vol. 58 (ed. Karlin, K. D.) 303-415 (Wiley, Hoboken, 2014).

41. Fryzuk, M. D., Haddad, T. S. \& Rettig, S. J. Reduction of dinitrogen by a zirconium phosphine complex to form a side-on-bridging $\mathrm{N}_{2}$ ligand. Crystal structure of $\left\{\left[\left(\mathrm{Pr}_{2}^{i} \mathrm{PCH}_{2} \mathrm{SiMe}_{2}\right)_{2} \mathrm{~N}\right] \mathrm{ZrCl}\right\}_{2}\left(\mu-\eta^{2}: \eta^{2}-\mathrm{N}_{2}\right)$. J. Am. Chem. Soc. 112, 8185-8186 (1990).

42. Ohki, Y. \& Fryzuk, M. D. Dinitrogen activation by group 4 metal complexes. Angew. Chem. Int. Ed. 46, 3180-3183 (2007).

43. Tanabe, Y., Kuwata, S. \& Ishii, Y. Syntheses and skeletal transformations of NCNH- and NCN-bridged tetrairidium(III) cages. J. Am. Chem. Soc. 124, 6528-6529 (2002).

44. Schmidt, A.-C., Heinemann, F. W., Lukens, W. W. Jr \& Meyer, K. Molecular and electronic structure of dinuclear uranium bis- $\mu$-oxo complexes with diamond core structural motifs. J. Am. Chem. Soc. 136, 11980-11993 (2014).

45. Reynolds, J. G., Zalkin, A., Templeton, D. H. \& Edelstein, N. M. Syntheses and crystal structures of tetrakis(diphenylamido)uranium(IV) and bis $(\mu$ -oxo-tris(diphenylamido)uranium(Iv)lithium diethyl etherate. Inorg. Chem. 16, 1090-1096 (1977). 


\section{Acknowledgements}

The authors acknowledge support from the Swiss National Science Foundation (grant nos. 200021_162430 and 200021_178793) and from the Ecole Polytechnique Fédérale de Lausanne (EPFL). The authors thank Euro Solari for carrying out the elemental analyses, L.Y.M. Eymann for synthesis of the $\mathrm{IMesN}_{2} \mathrm{O}$ adduct and R. Scopelliti for important contributions to the $\mathrm{X}$-ray single-crystal structure analyses.

\section{Author contributions}

M.F. and L.B. carried out the synthetic experiments and analysed the experimental data. J.A. performed preliminary experiments and characterized the U-O-U complexes. F.F.T. carried out the X-ray single-crystal structure analyses. I.Z. measured and analysed the magnetic data. A.F. and C.C. performed the theoretical computations. K.S. contributed to the identification of a new route to oxo complexes and provided the carbene compound. M.M. originated the central idea, coordinated the work and analysed the experimental data. M.M., F.M. and L.B. wrote the manuscript.

\section{Competing interests}

The authors declare no competing interests.

\section{Additional information}

Supplementary information is available for this paper at https://doi.org/10.1038/ s41557-018-0167-8.

Reprints and permissions information is available at www.nature.com/reprints. Correspondence and requests for materials should be addressed to M.M.

Publisher's note: Springer Nature remains neutral with regard to jurisdictional claims in published maps and institutional affiliations.

(C) The Author(s), under exclusive licence to Springer Nature Limited 2018 


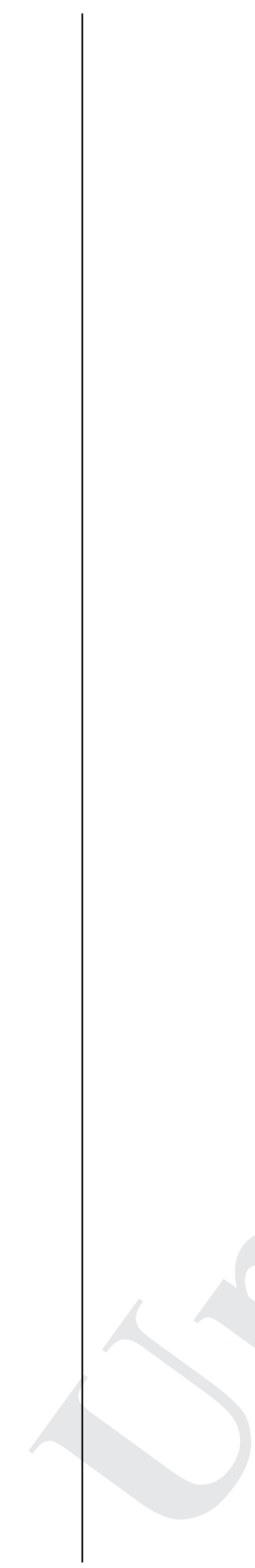

